\title{
A Note on the Semi-Inverse Method and a Variational Principle for the Generalized KdV-mKdV Equation
}

\author{
Li Yao, ${ }^{1}$ Yun-Jie Yang, ${ }^{1}$ and Xing-Wei Zhou ${ }^{1,2}$ \\ ${ }^{1}$ Department of Mathematics, Kunming University, 2 Puxin Road, Kunming, Yunnan 650214, China \\ ${ }^{2}$ Institute of Nonlinear Analysis, Kunming University, 2 Puxin Road, Kunming, Yunnan 650214, China \\ Correspondence should be addressed to Xing-Wei Zhou; km_xwzhou@163.com
}

Received 1 January 2013; Revised 5 January 2013; Accepted 27 January 2013

Copyright (C) $2013 \mathrm{Li}$ Yao et al. This is an open access article distributed under the Creative Commons Attribution License, which permits unrestricted use, distribution, and reproduction in any medium, provided the original work is properly cited.

Ji-Huan He systematically studied the inverse problem of calculus of variations. This note reveals that the semi-inverse method also works for a generalized $\mathrm{KdV}-\mathrm{mKdV}$ equation with nonlinear terms of any orders.

\section{Introduction}

In [1], the semi-inverse method is systematically studied and many examples are given to show how to establish a variational formulation for a nonlinear equation. From the given examples, we found that it is difficult to find a variational principle for nonlinear evolution equations with nonlinear terms of any orders.

For example, consider the following generalized KdVmKdV equation:

$$
u_{t}+\left(\alpha+\beta u^{p}+\gamma u^{2 p}\right) u_{x}+u_{x x x}+\eta u_{x x x x x}+g(t) u=0
$$

where $\alpha, \beta, \gamma$, and $\eta$ are constant coefficients, while $p$ is a positive number. Equation (1) is an important model in plasma physics and solid state physics.

\section{Variational Principle by He's Semi-Inverse Method}

For (1), we introduce a potential function $v$ defined as $u=v_{x}$; we have the following equation:

$$
\begin{aligned}
v_{x t}+(\alpha & \left.+\beta v_{x}^{p}+\gamma v_{x}^{2 p}\right) v_{x x}+v_{x x x x}+\eta v_{x x x x x x} \\
& +g(t) v_{x}=0 .
\end{aligned}
$$

In order to use the semi-inverse method [1-4] to establish a Lagrangian for (2), we first check some simple cases:

$$
\begin{gathered}
L=-\frac{v_{x} v_{t}}{2} \quad \text { for } v_{x t}=0, \\
L=\frac{\left(v_{x x}\right)^{2}}{2} \quad \text { for } v_{x x x x}=0, \\
L=-\frac{v_{x}^{3}}{6} \quad \text { for } \frac{\left(v_{x}^{2}\right)_{x}}{2}=v_{x} v_{x x}=0, \\
L=-\frac{v_{x}^{n}}{n(n-1)} \quad \text { for } v_{x}^{n-2} v_{x x}=0 .
\end{gathered}
$$

We can easily obtain a variational principle for (2) for $g(t) \equiv$ 0 , which is

$$
\begin{aligned}
J(v)=\iint\{ & \left\{\frac{1}{2} v_{x} v_{t}-\frac{1}{2} \alpha v_{x}^{2}-\frac{\beta}{(p+2)(p+1)} v_{x}^{p+2}\right. \\
& \left.-\frac{\gamma}{(2 p+2)(2 p+1)} v_{x}^{2 p+2}+v_{x x}^{2}-\frac{\eta}{2} v_{x x x}^{2}\right\} d x d t,
\end{aligned}
$$


Now, according to the semi-inverse method [1-4], we construct a trial functional for (2):

$$
\begin{aligned}
J(v)=\iint\{f(t)[ & -\frac{1}{2} v_{x} v_{t}-\frac{1}{2} \alpha v_{x}^{2}-\frac{\beta}{(p+2)(p+1)} v_{x}^{p+2} \\
& -\frac{\gamma}{(2 p+2)(2 p+1)} v_{x}^{2 p+2}+v_{x x}^{2} \\
& \left.\left.-\frac{\eta}{2} v_{x x x}^{2}\right]+F\right\} d x d t
\end{aligned}
$$

where $F$ is an unknown function of $u$ and/or its derivatives.

Making the trial-functional, (5), stationary with respect to $v$ results in the following Euler-Lagrange equation:

$$
\begin{aligned}
\frac{1}{2}\left(f v_{x}\right)_{t} & +\frac{1}{2}\left(f v_{t}\right)_{x}+\alpha\left(f v_{x}\right)_{x}+\frac{\beta}{(p+1)}\left(f v_{x}^{p+1}\right)_{x} \\
& +\frac{\gamma}{(2 p+1)}\left(f v_{x}^{2 p+1}\right)_{x}+\left(f v_{x x}\right)_{x x}-\eta\left(f v_{x x x}\right)_{x x x} \\
+ & \frac{\delta F}{\delta v}=0
\end{aligned}
$$

where $\delta F / \delta v$ is called variational differential with respect to $v$, defined as

$$
\begin{aligned}
\frac{\delta F}{\delta v}= & \frac{\partial F}{\partial v}-\frac{\partial}{\partial t}\left(\frac{\partial F}{\partial v_{t}}\right)-\frac{\partial}{\partial x}\left(\frac{\partial F}{\partial v_{x}}\right)+\frac{\partial^{2}}{\partial t^{2}}\left(\frac{\partial F}{\partial v_{t t}}\right) \\
& +\frac{\partial^{2}}{\partial x^{2}}\left(\frac{\partial F}{\partial v_{x x}}\right)+\cdots
\end{aligned}
$$

We rewrite (6) in the form

$$
\begin{gathered}
\frac{f_{t}}{2 f} v_{x}+v_{x t}+\alpha v_{x x}+\beta v_{x}^{p} v_{x x}+\gamma v_{x}^{2 p} v_{x x}+v_{x x x x} \\
+\eta v_{x x x x x x}+\frac{\delta F}{f \delta v}=0 .
\end{gathered}
$$

Comparison of (8) and (2) leads to the following results:

$$
\frac{f_{t}}{2 f}=g(t), \quad \frac{\delta F}{f \delta v}=0,
$$

from which we identify the unknown $f$ and $F$ as follows:

$$
f(t)=e^{2 \int g(t) d t}, \quad F=0 .
$$

We, therefore, obtain the following needed variational principle:

$$
\begin{gathered}
J(v)=\iint\left\{e ^ { 2 \int g ( t ) d t } \left[-\frac{1}{2} v_{x} v_{t}-\alpha v_{x}^{2}-\frac{\beta}{(p+2)(p+1)} v_{x}^{p+2}\right.\right. \\
-\frac{\gamma}{(2 p+2)(2 p+1)} v_{x}^{2 p+2}+v_{x x}^{2} \\
\left.\left.-\frac{\eta}{2} v_{x x x}^{2}\right]\right\} d x d t .
\end{gathered}
$$

\section{Conclusion}

This note shows that the semi-inverse method in [1] works also for the present problem, and it is concluded that the semi-inverse method is a powerful mathematical tool to the construction of a variational formulation for a nonlinear equation; illustrating examples are available in [5-10].

The semi-inverse method can be extended to fractional calculus [11-14].

\section{Acknowledgments}

This work was supported by the Chinese Natural Science Foundation Grant no. 10961029 and Kunming University Research Fund (2010SX01).

\section{References}

[1] J.-H. He, "Asymptotic methods for solitary solutions and compactons," Abstract and Applied Analysis, vol. 2012, Article ID 916793, 130 pages, 2012.

[2] J.-H. He, "An elementary introduction to recently developed asymptotic methods and nanomechanics in textile engineering," International Journal of Modern Physics B, vol. 22, pp. 3487-3578, 2008.

[3] J.-H. He, "Some asymptotic methods for strongly nonlinear equations," International Journal of Modern Physics B, vol. 20, no. 10, pp. 1141-1199, 2006.

[4] J.-H. He, "Variational principles for some nonlinear partial differential equations with variable coefficients," Chaos, Solitons \& Fractals, vol. 19, no. 4, pp. 847-851, 2004.

[5] L. Yao, "How to discover a variational principle for a damped vibration problem," International Journal of Nonlinear Sciences and Numerical Simulation, vol. 11, pp. 171-173, 2010.

[6] G.-C. Wu, "Laplace transform overcoming principle drawbacks in application of the variational iteration method to fractional heat equations," Thermal Science, vol. 16, no. 4, pp. 1257-1261, 2012.

[7] X.-W. Zhou and L. Wang, "A variational principle for coupled nonlinear Schrödinger equations with variable coefficients and high nonlinearity," Computers \& Mathematics with Applications, vol. 61, no. 8, pp. 2035-2038, 2011.

[8] Z.-L. Tao, "Variational approach to the Benjamin Ono equation," Nonlinear Analysis. Real World Applications, vol. 10, no. 3, pp. 1939-1941, 2009.

[9] Z.-L. Tao, "Solitary solutions of the Boiti-Leon-MannaPempinelli equation using He's variational method," Zeitschrift fur Natuforschung A, vol. 63, no. 10-11, pp. 634-636, 2008.

[10] L. Xu, "Variational approach to solitons of nonlinear dispersive $\mathrm{K}(\mathrm{m}, \mathrm{n})$ equations," Chaos, Solitons and Fractals, vol. 37, no. 1, pp. 137-143, 2008.

[11] D. Baleanu and S. I. Muslih, "Lagrangian formulation of classical fields within Riemann-Liouville fractional derivatives," Physica Scripta, vol. 72, no. 2-3, pp. 119-121, 2005.

[12] D. Baleanu, K. Diethelm, E. Scalas, and J. J. Trujillo, Fractional Calculus Models and Numerical Methods, vol. 3, World Scientific, 2012. 
[13] G.-C. Wu and D. Baleanu, "Variational iteration method for the Burgers' flow with fractional derivatives-new Lagrange Mutipliers," Applied Mathematical Modelling, vol. 37, no. 9, pp. 6183-6190, 2013.

[14] G.-C. Wu, "New trends in variational iteration method," Communications in Fractional Calculus, vol. 2, no. 2, pp. 59-75, 2011. 


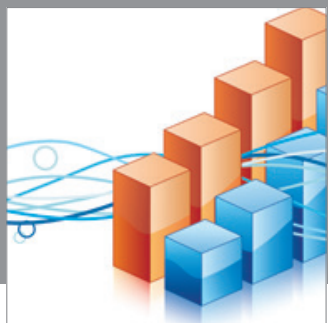

Advances in

Operations Research

mansans

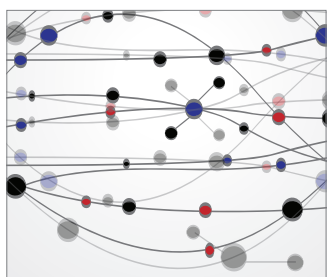

The Scientific World Journal
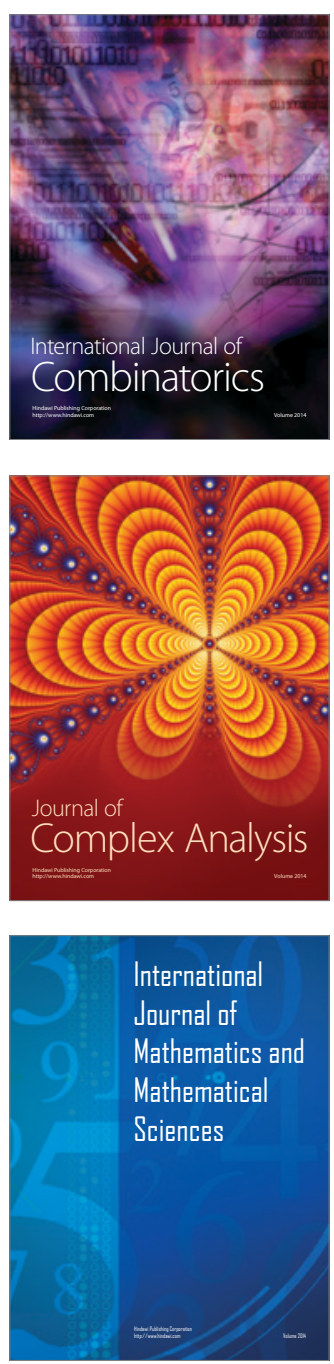


Submit your manuscripts at http://www.hindawi.com
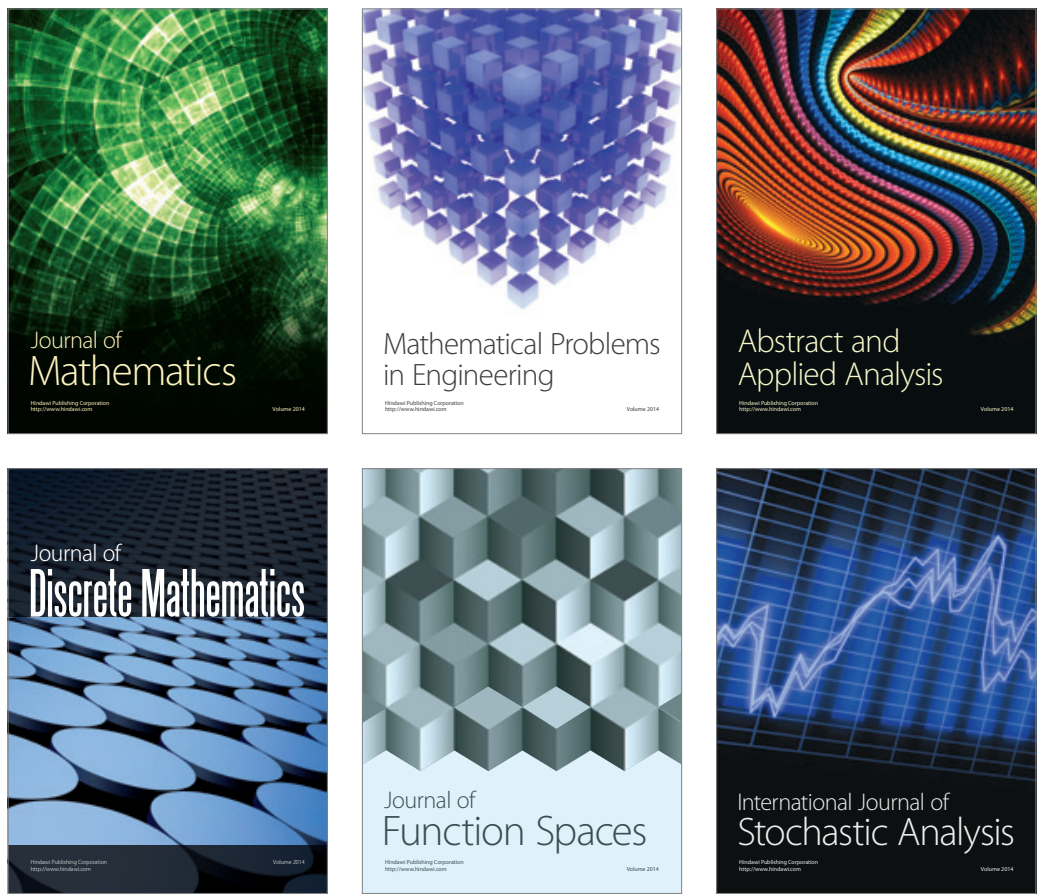

Journal of

Function Spaces

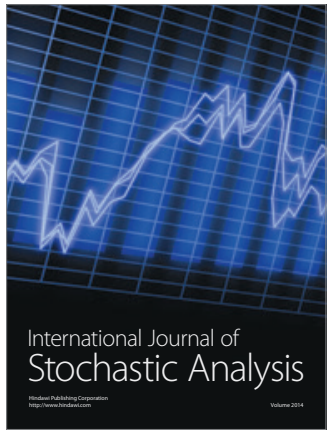

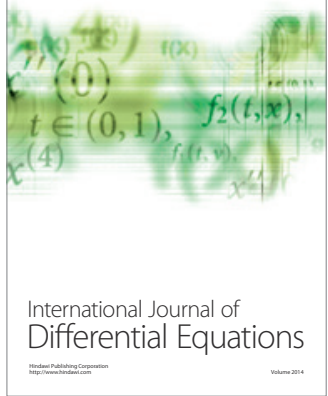
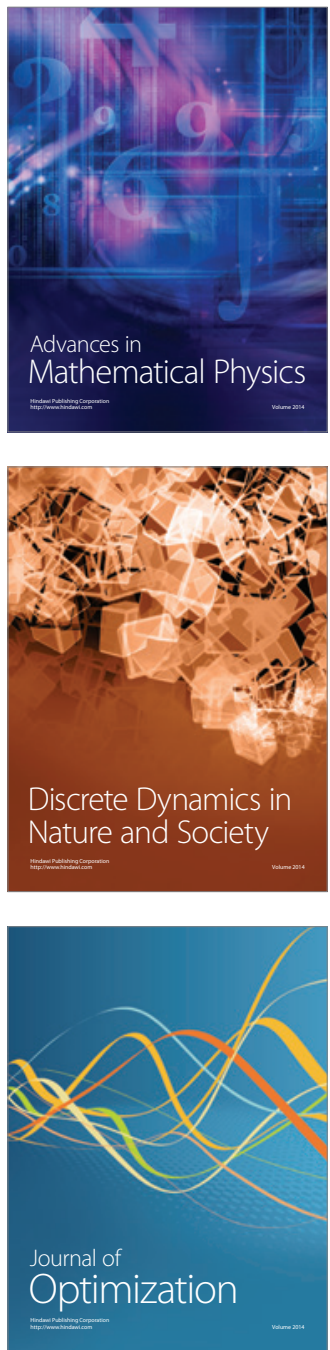